\section{The Bertelsmann Foundation's Center for Higher Education Development}

\section{Detlef Müller-Böling}

Detlef Müller-Böling is director of the nonprofit Center for Higher Education Development. Address: P.O. Box 105, Carl-Bertelsmann-Str. 256, D-33311 Gütersloh, Germany. Phone: 49/5241-9761-21 or 49/ 5241-9761-4. E-mail: <susanne.dopheide@bertelsmann.de>.

$\mathrm{T}$ o initiate and support reform in the German higher education system, the Bertelsmann Foundation and the German Rectors' Conference founded the Center for Higher Education Development in 1994. The CHE seeks to define politically independent objectives, to develop concrete strategies to realize these objectives, and to test the extent to which change can be introduced. As a nonprofit limited-liability company, the Center is in a position to act independently of individual or political interests. Furthermore, the CHE is committed to the common good in both financial and idealistic terms.

The overarching objective of the CHE is to promote the efficiency of German universities and their capacity to evolve. Structural problems within the postsecondary system-such as increasing numbers of students and underfunding-require revolutionary changes in educational policy. This will involve the breaking of longstanding taboos. These include, among other things, decreasing state regulation, improving research and teaching conditions, reorganizing access to postsecondary education, introducing tuition fees, delegating responsibility to all levels of the system and privatizing certain parts, strengthening postsecondary management, and, finally, bringing alternative principles and models of higher education into consideration.

The CHE regards itself as both a think tank and a consultant to higher education. Its objectives are to develop models for performance-oriented and competitive management of higher education, and to foster acceptance of these new management approaches within institutions of higher education and in society at large. In this context it is necessary to examine higher education practices and initiatives in other countries and consider their relevance and transferability to the German setting.

Three different approaches characterize CHE's work: creating pilot projects involving individual postsecondary institutions and relevant state agencies; introducing concrete reform proposals into the public debate on such issues as higher education access and financing; and organizing symposia and workshops to further the exchange of information between higher education institutions.

The CHE describes the university of the future as being autonomous, academic, competitive and based on competitive market principles, each one with its own distinctive profile. The goal of the "pilot" projects is to define these principles and integrate them into the German higher education system. These basic elements fall into several broad areas.

\section{Organization}

The area of university organization concerns designing the leadership and the administrative structure of universities so as to achieve institutional autonomy with public accountability. Central aspects include the support of strategic and developmental planning, the trial decentralization of administration, and the creation of more effective and efficient administration processes.

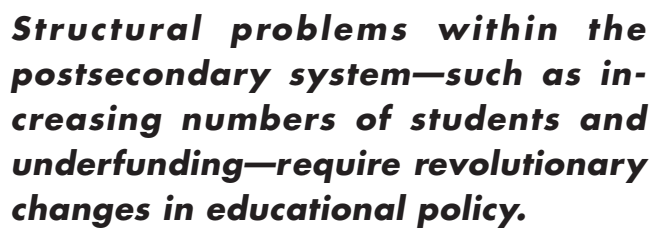

\section{Performance Standards}

The purpose of this area is to improve the leadership capacity of universities through a comparative analysis. Developing performance standards will create a basis for comparison of higher educational institutions both nationally and internationally. The object is not only to foster competition, but to create measures that are fully comprehensible for three target audiences: high school graduates, employers, and university heads.

\section{Efficiency}

The CHE encourages universities to make efficient use of their financial resources. This will require changing to a system in which cost awareness and budget responsibility are central.

\section{Competition}

Competition among universities can only be promoted and supported if an appropriate framework is in place. Without the creation of competitive elements in the German system, increased performance cannot be expected. Successful competition would be reflected in student demand and the willingness of students to pay fees. Thus, CHE's activities in this area focus on university access requirements and introducing tuition fees. 